\title{
The role of titanium and vanadium based precipitates on hydrogen induced degradation of ferritic materials
}

\author{
A. Laureys ${ }^{\mathrm{a}}$, L. Claeys ${ }^{\mathrm{a}}$, T. De Seranno ${ }^{\mathrm{a}}$, T. Depover ${ }^{\mathrm{a}}$, E. Van den Eeckhout ${ }^{\mathrm{a}}$, R. Petrov ${ }^{\mathrm{b}, \mathrm{c}}$, \\ K. Verbeken ${ }^{\mathrm{a}, *}$ \\ a Department of Materials, Textiles and Chemical Engineering, Ghent University (UGent), Tech Lane Ghent Science Park, Campus A, Technologiepark 903, B-9052 Gent, \\ Belgium \\ ${ }^{\mathrm{b}}$ Department of Electrical Energy, Metals, Mechanical constructions \& Systems, Ghent University (UGent), Tech Lane Ghent Science Park. Campus A, Technologiepark \\ 903, B-9052 Gent, Belgium \\ ${ }^{\mathrm{c}}$ Department of Materials Science and Engineering, Delft University of Technology, Mekelweg 2, 2628 CD Delft, the Netherlands
}

A R T I C L E I N F O

\section{Keywords:}

Hydrogen induced damage

EBSD

Precipitate

SEM

Hydrogen blistering

\begin{abstract}
A B S T R A C T
The hydrogen induced damage of generic Fe-C-Ti and Fe-C-V ferritic alloys was investigated to assess the influence of precipitates on the hydrogen sensitivity of a material. The precipitates, formed during heat treatment, were evaluated by scanning transmission electron microscopy (STEM). The hydrogen/material interaction was evaluated by: 1) melt and hot extraction to determine the total and diffusible hydrogen content, respectively, 2) permeation experiments to calculate the diffusion coefficient, 3) thermal desorption spectroscopy to determine the hydrogen trapping characteristics of the materials. Furthermore, two different types of hydrogen induced damage were evaluated, i.e. hydrogen assisted cracking and blistering, resulting from electrochemical hydrogen charging with and without the application of an external load, respectively. Evaluation of the hydrogen induced damage and the role of the precipitates was performed by combining optical microscopy, scanning electron microscopy (SEM), and electron backscatter diffraction (EBSD). An important though divertive role of diffusible hydrogen is observed in both damage mechanisms for the investigated microstructures. On the one hand, a large amount of diffusible hydrogen compared to strongly trapped hydrogen promotes hydrogen assisted cracking of materials, while on the other hand, the blistering phenomenon is delayed under such conditions.
\end{abstract}

\section{Introduction}

It is well-documented that hydrogen has a detrimental effect on the mechanical properties of steels, especially in terms of plasticity as a significant ductility loss might be introduced by small amounts of hydrogen $[1,2]$. This phenomenon is often referred to as hydrogen embrittlement (HE) or hydrogen assisted cracking (HAC). Hydrogen assisted cracking is defined as fracture of a material at subcritical stress levels (e.g. before reaching the ultimate tensile stress of the material) due to embrittlement of highly stressed regions ahead of cracks or notches caused by an, although still rather low, increased hydrogen concentration [3]. A prerequisite for hydrogen assisted cracking is diffusion of a sufficient amount of hydrogen towards the critical crack tip zone from the surrounding microstructure in order to maintain embrittlement [4]. Introducing efficient hydrogen traps is assumed to reduce the hydrogen embrittlement (HE) susceptibility as it lowers the amount of diffusible hydrogen, which primarily contributes to the hydrogen induced ductility loss [5-9]. Therefore, the presence of precipitates in a material, such as carbides, is claimed to have a beneficial effect on the HE sensitivity $[8,10]$. Titanium carbide (TiC) and vanadium carbide (VC or $\mathrm{V}_{4} \mathrm{C}_{3}$ ) have been reported to be beneficial to improve the resistance to $\mathrm{HE}$ due to their relatively strong hydrogen trapping capacity $[8,11-14]$. Several precipitate related trapping sites have been proposed, i.e. the strain field surrounding a (semi-)coherent particle, the coherent or incoherent interface with the matrix and the interior of the particle. As such, it has been demonstrated that particles show a different trapping behavior depending on their type, size, morphology, and interface characteristics [15, 16]. Carbide addition could be of special interest for advanced high strength steels, for which hydrogen induced degradation can occur at very low hydrogen concentrations of only a few ppm [17]. Such low concentrations can easily be reached during processing or in use. Addition of carbides could mitigate the problem by offering efficient and strong hydrogen trapping sites. This is only valid in case the hydrogen supply from the

\footnotetext{
* Corresponding author.

E-mail addresses: aurelie.laureys@ugent.be (A. Laureys), lisa.claeys@ugent.be (L. Claeys), tim.deseranno@ugent.be (T. De Seranno), tom.depover@ugent.be (T. Depover), emilie.vandeneeckhout@ugent.be (E. Van den Eeckhout), roumen.petrov@ugent.be (R. Petrov), kim.verbeken@ugent.be (K. Verbeken).
} 
environment is not continuous [18]. However, opposed to the beneficial effect of precipitates, they trap and therefore accumulate hydrogen and consequently, might also be preferential initiation sites for hydrogen induced cracks [19, 20]. Hydrogen induced cracking can occur in metals subjected to high fugacity hydrogen environments, such as high pressure hydrogen gas environments or under extreme cathodic charging conditions, even without the application of an external load [21, 22]. Hydrogen flakes as found in reactor pressure vessels [23] are also an example of hydrogen induced cracking. The internal pressure theory [24-26] states that hydrogen induced cracking results from the formation of high pressure hydrogen gas bubbles in internal voids and microcracks. When an alloy is exposed to a hydrogen environment, atomic hydrogen is absorbed in the metal and diffuses inside. Its movement can be interrupted by microstructural discontinuities, such as voids, second phase particles, grain boundaries, and microcracks, which act as trap sites [27]. At such sites, atomic hydrogen can recombine to form molecular gaseous hydrogen, which is incapable of further migration and locally creates a very high internal pressure [28]. The result is the formation of overpressurized gas-filled cavities, which cause plastic deformation of the surrounding lattice and promote crack formation. If the internal pressure rises to levels which exceed the tensile strength, crack propagation occurs, even in the absence of externally applied loads. When the phenomenon takes place close to the sample surface, it is referred to as blistering. The high pressure then pushes material upwards, resulting in a surface blister [21]. In order for such cracking to occur, a certain amount of trapped hydrogen at microstructural heterogeneities is required with each trap exhibiting its own critical hydrogen concentration [29]. Hydrogen induced blister and internal crack formation in materials was already numerous times linked to the presence of particles, such as $\mathrm{MnS}$ and $\mathrm{Al}_{2} \mathrm{O}_{3}[21,22,30$, 31].

Wei et al. [15, 32] characterized the hydrogen trapping behavior of TiC particles with varying interface coherency in steel by thermal desorption spectroscopy (TDS). The activation energy for desorption was remarkably smaller for coherent particles $(46-59 \mathrm{~kJ} / \mathrm{mol})$ in comparison to incoherent particles $(68-116 \mathrm{~kJ} / \mathrm{mol})$. Pressouyre and Bernstein [33] stated that at room temperature incoherent TiC particles act as irreversible trapping sites, while substitutional titanium, grain boundaries and dislocations act as reversible traps. Dey et al. [34] demonstrated that hydrogen atoms have a high solubility at the interface between carbides and matrix material. This was later confirmed by the work of Takahashi et al. [35], who performed a direct observation of deuterium atoms trapped along the broad surfaces of nano-sized, (semi) coherent TiC platelets in ferritic steel by using atom probe tomography. As the side interfaces gradually lost their coherency upon precipitate growth, a simultaneous increase in the trapping activation energy $E_{t}$ and the binding energy $E_{b}$ was observed. On the one hand, an increase in the trapping activation energy $E_{t}$, i.e. the energy barrier for trapping, makes hydrogen trapping more challenging by cathodic charging at room temperature, while on the other hand, an increase in the binding energy $E_{b}$ enhances the capability of hydrogen absorption from the atmosphere during heat treatment. Pérez Escobar et al. [36] found that after hot and cold rolling some hydrogen is irreversibly trapped at the incoherent TiC precipitates. After a consecutive annealing treatment in a gaseous hydrogen atmosphere, the incoherent $\mathrm{TiC}$ precipitate size increased and even more hydrogen was irreversibly trapped, as confirmed by TDS. Electrochemical charging at room temperature, however, only led to reversible hydrogen trapping, for instance at grain boundaries. Depover et al. [14] also stated that incoherent particles are not able to trap hydrogen during electrochemical charging at room temperature, whereas small coherent TiC particles trapped hydrogen at their interface with the matrix. Wei et al. [15] indicated that incoherent TiC particles trap hydrogen during heat treatment at high temperature within them rather than at the particle/matrix interface. They supposed that octahedral carbon vacancies are the hydrogen trapping sites in incoherent TiC particles. The probability of having carbon vacancies is larger with increasing particle size, making hydrogen trapping inside the precipitate more advantageous in the case of incoherent particles [18]. Carbon vacancies in the interior of titanium carbides were found to be much stronger traps than the interfaces of titanium carbides [18]. Hickel et al. [37] performed ab initio calculations with density functional theory (DFT) to investigate the possibility of hydrogen trapping by the interfaces between a bcc iron matrix and different carbides and nitrides. They observed that the hydrogen adsorption energy at the interface between bcc iron and carbides/nitrides was negative, suggesting a spontaneous hydrogen segregation to those type of interfaces. Di Stefano et al. [18] illustrated by ab initio calculations with DFT that hydrogen has a low solubility in carbides and nitrides with respect to the hydrogen solubility in the bcc iron matrix. Insertion of hydrogen in titanium carbides and nitrides makes the initial bonds energetically less stable and therefore requires energy. In contrast, the addition of hydrogen on interfaces of carbides and nitrides could passivate non-saturated bonds. Dey et al. [34] also found that the adsorption energy is negative at several possible positions along the ferrite/TiC interface, indicating a strong driving force for hydrogen to segregate at this interface.

Takahashi et al. [38] found that vanadium carbides in vanadium carbide precipitation ferritic steel have a chemical composition of $\mathrm{V}_{4} \mathrm{C}_{3}$ and Spencer and Duquette [12] made the same conclusion for quenched and tempered steels. This observation indicated a high number density of carbon vacancies under thermal equilibrium conditions for this precipitate. The empty carbon sites of the $\mathrm{V}_{4} \mathrm{C}_{3}$ can act as physical traps for hydrogen [5, 38-40], in order to improve the hydrogen embrittlement resistance of steels [12]. Takahashi et al. [38] used atom probe tomography with a deuterium-charging method to directly observe hydrogen trapping sites in vanadium carbides in ferritic steel. Deuterium atoms were observed near the broad surfaces of semi-coherent carbide platelets, while at coherent carbides, no deuterium atoms were observed. Their conclusion was that the trapping sites are the misfit dislocation cores at the semi-coherent surfaces of the vanadium carbide platelets. Furthermore, the very high diffusion barrier of vanadium carbides prevented deuterium atoms from diffusing deeply into the precipitate and getting trapped inside. Malard et al. [41] used smallangle neutron scattering to establish that hydrogen is trapped inside the vanadium carbides rather than at the precipitate/matrix interface in an austenitic Fe-Mn-C twinning-induced plasticity (TWIP) steel. They concluded that vanadium carbides are reasonably effective irreversible hydrogen traps that can take up a few ppm hydrogen. Depover et al. [11] also concluded based on a TDS study that hydrogen might be trapped inside vanadium carbides at the carbon vacancies in $\mathrm{V}_{4} \mathrm{C}_{3}$.

Kawakami and Matsumiya [42] performed ab initio calculations and finite element modeling (FEM) to investigate the trapping potential of coherent TiC and $\mathrm{V}_{4} \mathrm{C}_{3}$ carbides in bcc iron. The strain field surrounding both $\mathrm{TiC}$ and $\mathrm{V}_{4} \mathrm{C}_{3}$ is a weak trapping site with the trapping energy slightly lower than interstitial positions. The coherent interface of TiC appears to be a quite stable trapping site, whereas the coherent interface of $\mathrm{V}_{4} \mathrm{C}_{3}$ is less stable compared to interstitial lattice sites. Interstitial lattice sites in both carbides are metastable sites as their energy is higher than for interstitial bcc lattice sites. Carbon vacancies in both carbides appear to be the strongest trapping sites. However, these strong trapping sites are not very effective because of the large diffusion barrier for hydrogen to enter the carbide. TiC is found to have a very low amount of carbon vacancies and hydrogen atoms have to diffuse far to reach carbon vacancies, while $\mathrm{V}_{4} \mathrm{C}_{3}$ has a lot of intrinsic carbon vacancies resulting in a smaller diffusion distance. Therefore, carbon vacancies in $\mathrm{V}_{4} \mathrm{C}_{3}$ are considered to be more active in trapping hydrogen than TiC, especially at low temperatures. This was confirmed by Di Stefano et al. [18] as well.

This work will study generic steels, i.e. Fe-C-V and Fe-C-Ti, consisting of a ferrite matrix with heat treatment induced precipitates to evaluate the effect of carbides and carbonitrides on the hydrogen assisted cracking and hydrogen induced cracking/blistering. These are 
two hydrogen related degradation processes which exhibit different damaging mechanisms. The role of precipitates acting as traps for diffusive hydrogen have to be examined carefully for both processes. On the one hand, precipitates take diffusible hydrogen out of the material microstructure by providing relatively deep trapping sites, decreasing the embrittlement vulnerability. On the other hand, precipitates provide regions with a locally increased hydrogen concentration, which could make them the ideal locations for crack initiation and possible propagation. The hydrogen content in the generic alloys was determined by hot and melt extraction. Permeation experiments and thermal desorption spectroscopy were performed to characterize the hydrogen diffusion and trapping behavior of both materials. The effect of precipitates was investigated for the two types of hydrogen damage. On the one hand, tensile tests with in-situ electrochemical hydrogen charging were performed to estimate hydrogen embrittlement and hydrogen assisted cracking. On the other hand, electrochemical hydrogen charging under more extreme charging conditions without the application of an external load was carried out in order to assess the blistering behavior of the alloys. Furthermore, the obtained hydrogen related cracks were investigated by optical microscopy, scanning electron microscopy (SEM) and electron backscatter diffraction (EBSD).

\section{Materials and Experimental Procedure}

Two laboratory cast, hot and cold rolled ferritic Fe-C-X materials were used. Casting was performed in a Pfeiffer VSG100 incremental vacuum melting and casting unit under a protective argon gas atmosphere. After hot and cold rolling, sheet material with a final thickness of $1 \mathrm{~mm}$ was obtained. The materials' compositions are shown in Table 1 , where the ternary carbide forming element $\mathrm{X}$ was either titanium or vanadium. A stoichiometric amount of the ternary alloying element was added with respect to the carbon content for the formation of $\mathrm{TiC}$ and $\mathrm{V}_{4} \mathrm{C}_{3}$ carbides. $\mathrm{Al}$ was added to bind the present nitrogen from casting, decreasing the chances of forming $\mathrm{Ti}$ or $\mathrm{V}$ based nitrides or carbonitrides [43]. The cold rolled materials were subjected to a specific heat treatment (Fig. 1) to obtain a ferritic matrix with precipitates. All alloying elements were brought as much as possible in solid solution at a high temperature of $1250^{\circ} \mathrm{C}$, after which controlled precipitation of carbides and ferrite formation took place at a second isothermal holding temperature of $800{ }^{\circ} \mathrm{C}$ and subsequent slow cooling. A ferritic matrix allows to study the effect of precipitates without the additional trapping effects of boundaries, such as martensitic lath boundaries, or the presence of an increased dislocation density.

Hot and melt extraction were used to determine the diffusible and total amount of hydrogen present in the materials, respectively. The materials were electrochemically charged at a current density of $0.8 \mathrm{~mA} / \mathrm{cm}^{2}$ for $1 \mathrm{~h}$ in a $0.5 \mathrm{M} \mathrm{H}_{2} \mathrm{SO}_{4}-1 \mathrm{~g} / \mathrm{l}$ thiourea electrolyte. Discs of $20 \mathrm{~mm}$ diameter were used for hot extraction, while rectangular samples of $6 \times 8 \times 1 \mathrm{~mm}^{3}$ were used for melt extraction. Hot extraction was executed at $300^{\circ} \mathrm{C}$, since diffusible hydrogen is defined as hydrogen that desorbs below $300^{\circ} \mathrm{C}[44,45]$, while melt extraction was performed at $1550{ }^{\circ} \mathrm{C}$. Both tests were performed in a Galileo G8 set-up.

Hydrogen electrochemical permeation tests were performed according to the Devanathan and Stachurski method [46] to determine the apparent hydrogen diffusion coefficient. The permeation cell consisted of two compartments filled with $0.1 \mathrm{M} \mathrm{NaOH}$ electrolyte solution. This electrolyte differs from the one used for hydrogen charging of the samples since the applied current density and long duration of the

Table 1

Chemical composition of Fe-C-X alloys, with $\mathrm{X}$ being Ti or V.

\begin{tabular}{llllll}
\hline $\mathrm{Wt} \%$ & $\mathrm{C}$ & $\mathrm{X}$ & $\mathrm{N}$ & $\mathrm{Al}$ & $\mathrm{Fe}$ \\
\hline Fe-C-Ti & 0.1 & 0.38 & 0.005 & 0.03 & Balance \\
Fe-C-V & 0.1 & 0.57 & 0.0045 & 0.03 & Balance \\
\hline
\end{tabular}

permeation test are likely to cause very significant hydrogen induced damage, which would make the obtained results invalid [22]. The two compartments were stirred with nitrogen bubbling and kept at ambient temperature. Polished circular samples $(20 \mathrm{~mm}$ diameter) with $1 \mathrm{~mm}$ thickness were clamped in between the compartments. At the hydrogen entry side, which acts as cathode, a current density of $3 \mathrm{~mA} / \mathrm{cm}^{2}$ was applied, while the hydrogen exit side was potentiostatically kept at $-500 \mathrm{mV}$ with respect to a $\mathrm{Hg} / \mathrm{Hg}_{2} \mathrm{SO}_{4}$ reference electrode. From such tests a permeation curve with the normalized current as a function of time was generated. The apparent hydrogen diffusion coefficient could be calculated from the permeation curve using the following formula [46]:

$D_{\text {app }}=\frac{L^{2}}{7.7 * t}$

where $t$ is the time (s) when the normalized steady-state value has reached 0.1 and $L$ is the specimen thickness (m).

TDS was performed to identify the available hydrogen trapping sites. The charging conditions were chosen as described above for melt and hot extraction. A heating rate of $1200^{\circ} \mathrm{C} / \mathrm{h}$ was applied. The measured spectra were deconvoluted in order to identify the different traps.

Prior to hydrogen charging, surface oxides, which might have an inhibiting effect on hydrogen absorption in the metal and possibly have a role in the actual nucleation of hydrogen induced damage [47], were removed by grinding the sample surfaces. The materials were electrochemically charged in an electrolyte consisting of $0.5 \mathrm{M} \mathrm{H}_{2} \mathrm{SO}_{4}$ with $1 \mathrm{~g} / 1$ thiourea. During charging, the sample acted as cathode whereas the anodes were platinum foils present at both sides of the sample. On the one hand, hydrogen induced cracks and blisters were introduced in ground oval samples (long diameter of $20 \mathrm{~mm}$, oriented along the rolling direction) by hydrogen charging without the application of an external load. The samples were hydrogen charged for varying charging times and current densities to determine the conditions at which internal cracking and blistering occur. On the other hand, slow strain rate tensile tests with in-situ electrochemical charging were carried out in order to assess the hydrogen assisted cracking behavior under external load. As a reference, samples were also tested in air for comparison. For such tests notched tensile samples (Fig. 2) were used and a constant strain rate of $1.11 \times 10^{-5} \mathrm{~s}^{-1}$ was applied. Notched samples were used in order to control the fracture location. Previous work illustrated that the overall hydrogen assisted cracking characteristics did not alter in the presence of a notch [48]. In order to assess the hydrogen assisted cracking behavior under an externally applied load, polished samples were first pre-charged at a current density of $0.8 \mathrm{~mA} / \mathrm{cm}^{2}$ for $1 \mathrm{~h}$. The authors verified that hydrogen saturation was reached without damage introduction at these charging conditions. Subsequently, tensile tests were started under continuous hydrogen charging. Samples were both strained until reaching the tensile strength (interrupted tensile test) and until final fracture to evaluate crack initiation and further propagation.

Microstructural characterization was carried out by light optical microscopy, scanning electron microscopy (SEM) (Quanta FEG 450), electron backscatter diffraction (EBSD), and scanning transmission electron microscopy (STEM JEOL JEM-2200FS). STEM was applied on thin foils to determine the size distribution of the precipitates and combined with energy dispersive x-ray spectroscopy (EDX) to determine the compositions of the precipitates. Sample preparation was carried out following standard metallographic practices (up to $1 \mu \mathrm{m}$ polishing with diamond suspension) for light optical microscopy and SEM. EBSD requires flat specimens for which any residual deformation or stress in the surface layers due to mechanical polishing should be avoided [49]. To study blister cross sections an additional polishing step with colloidal silica (Struers OPU suspension) was applied. To study the surface cracks formed on the tensile samples, an explicit surface preparation was required since standard surface preparation would result in simultaneous removal of the cracks. Therefore, sample 


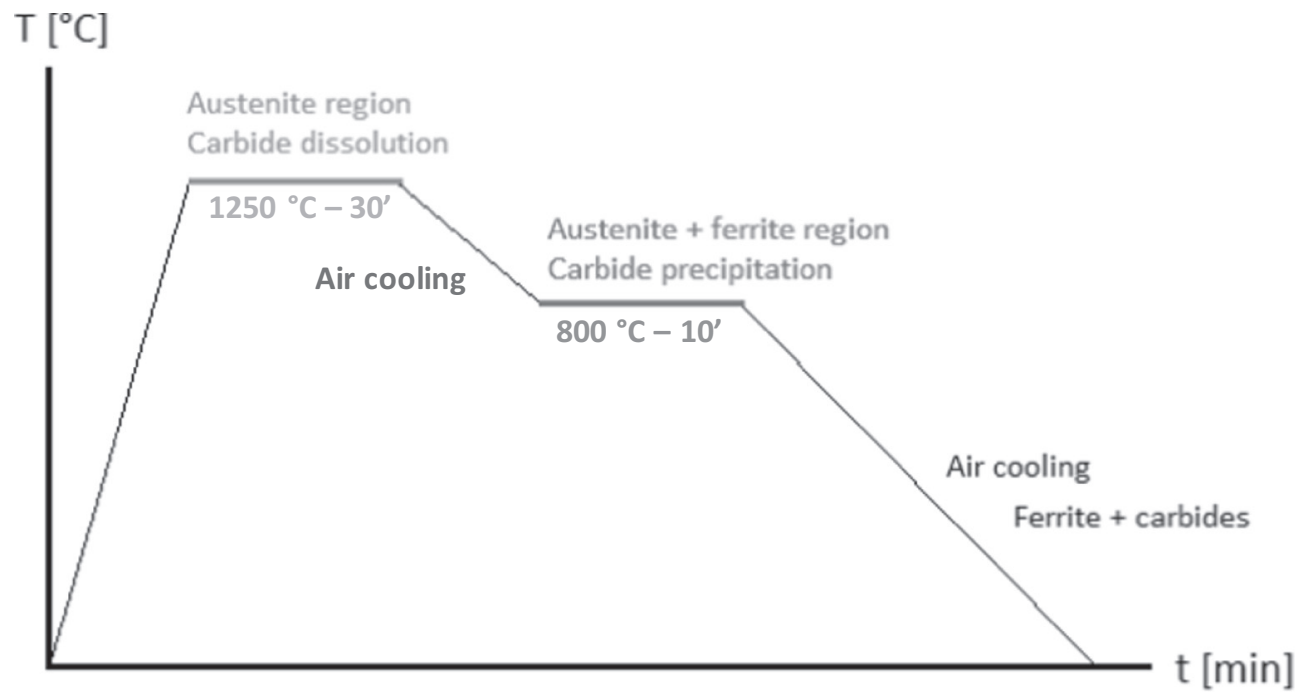

Fig. 1. Heat treatment performed on cold rolled plates.

preparation was optimized by grinding and polishing up to $1 \mu \mathrm{m}$ before tensile testing (and thus cracking). No additional grinding was necessary after tensile testing, but the sample surface had to be re-polished, in order to remove the surface damage caused by electrolyte attack. The 3 and $1 \mu \mathrm{m}$ diamond paste polishing steps were repeated, followed by an additional polishing step with colloidal silica (Struers OPU suspension) to obtain adequate surfaces for an EBSD study. Electropolishing was not performed in order to avoid rounding of the cracks. These measurements were performed at a tilt angle of $70^{\circ}$, spot size of $5 \mathrm{~nm}$, accelerating voltage of $20 \mathrm{kV}$, and a step size ranging from 0.1 to $0.02 \mu \mathrm{m}$ on a hexagonal grid. TSL-OIM Data Analysis V6.1 software was used for post processing and analysis of the orientation data. Inverse pole figures (IPF), kernel average misorientation (KAM) maps and phase maps were used during analysis. The measurements were partitioned on image quality, as such that partitioned points are attributed to cracked regions in the alloys. Applying the partition made the crack geometry better distinguishable on OIM maps. Thin foils for STEM were prepared by grinding and polishing up to $1 \mu \mathrm{m}$ diamond suspension to a thickness below $100 \mu \mathrm{m}$. Subsequently, the samples were electropolished with a $10 \%$ perchloric acid and $90 \%$ acetic acid solution.

\section{Results and Discussion}

\subsection{Microstructural Characterization}

The selected heat treatment resulted in a coarse grained ferritic matrix with numerous precipitates for both alloys (Fig. 3). In the Fe-C-V alloy, precipitates were too small to visualize on optical images (Fig. 3a). STEM and EDX showed that the material contained mostly small carbides $\left(\mathrm{V}_{4} \mathrm{C}_{3}[11,12,38]\right)(15-45 \mathrm{~nm})$ and some medium sized incoherent carbonitrides $(\mathrm{V}(\mathrm{C}, \mathrm{N}))(100 \mathrm{~nm}-1 \mu \mathrm{m})$ (Fig. 4). All precipitates in this alloy were plate shaped. Diffraction lobes were observed around the nanometer sized carbides, which indicates that the surrounding matrix is strained, i.e. strain contrast [50]. These strains indicate the coherent character of the small precipitates as the misfit is accomplished by strains in the matrix rather than the introduction of dislocations. These observations lead to the conclusion that the broad surfaces of these disc shaped carbides were coherent with the ferrite matrix. Takahashi et al. [38] stated that when the edge length of these small carbides exceeds $\sim 8 \mathrm{~nm}$ a misfit dislocation is released. Therefore, the $\mathrm{V}$ carbides are considered as semi-coherent particles. In the FeC-Ti alloys, numerous large particles could already be seen on the optical images (Fig. 3b). STEM and EDX identified these large particles as incoherent TiC particles $(2-5 \mu \mathrm{m})$. Performed solubility calculations $[11,14]$ illustrated that carbides, formed during casting and rolling, were not completely dissolved during the first step of the applied heat treatment in the Fe-C-Ti alloy, explaining the presence of large carbides in the final material. Contrary to the Fe-C-V alloy, where all $\mathrm{V}$ and $\mathrm{C}$ was confirmed to go in solid solution at the temperature used in the first step of the heat treatment. Additionally, small coherent carbides $(2-24 \mathrm{~nm})$ and medium-sized carbonitrides $(\mathrm{Ti}(\mathrm{C}, \mathrm{N}))(100-700 \mathrm{~nm})$ were found (Fig. 5). All Ti carbides were spherical, while some Ti carbonitrides were rectangular-shaped. The small (semi-)coherent carbides were expected to play the most prominent role in the current experiments, since Pérez Escobar et al. [8] demonstrated that incoherent carbides do not trap hydrogen when charged electrochemically.

\subsection{Hot and Melt Extraction}

The total and diffusible amount of hydrogen were measured by melt and hot extraction analysis (Fig. 6). The total hydrogen amount is higher in Fe-C-V than in Fe-C-Ti. Diffusible hydrogen contributed to about $30 \%$ of the amount of charged hydrogen for Fe-C-Ti, whereas this contribution was about $70 \%$ for Fe-C-V. These results imply that hydrogen is trapped more strongly in Fe-C-Ti than in the V-based alloy, as such reducing the fraction of diffusible hydrogen, which is considered to be the most harmful type of hydrogen [20]. This strongly trapped
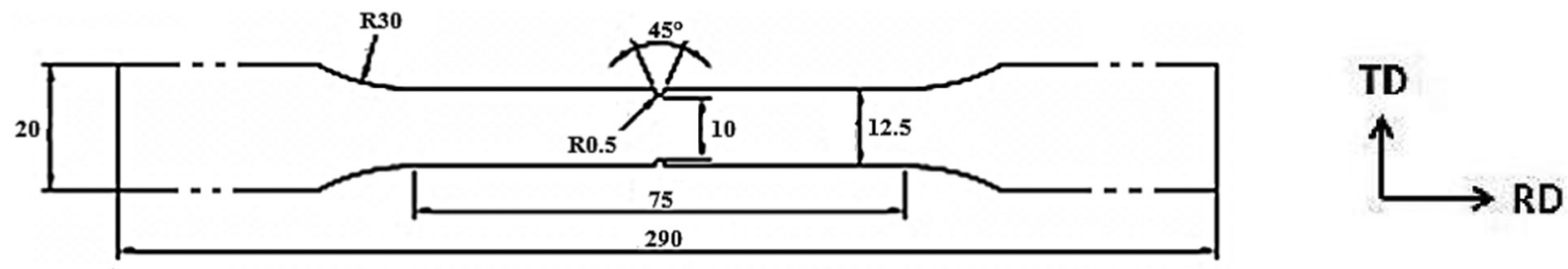

Fig. 2. Flat tensile sample geometry of notched tensile samples (in mm). 


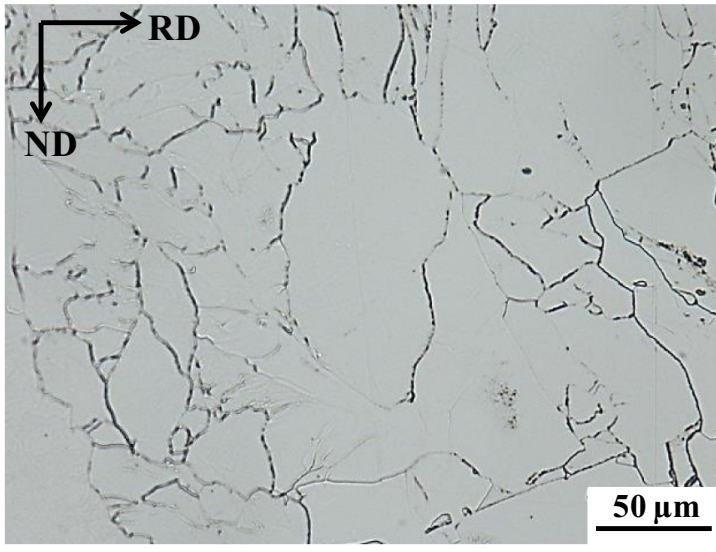

a)

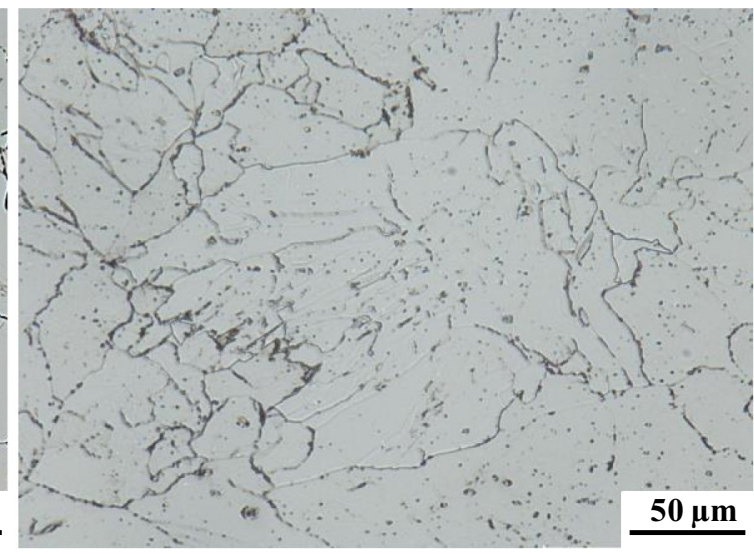

b)

Fig. 3. Microstructure of a) Fe-C-V and b) Fe-C-Ti alloy.

hydrogen is only released from the materials upon heating above $300{ }^{\circ} \mathrm{C}$ or upon melting. Wei and Tsuzaki [51] stated that the hydrogen trapping capacity at titanium carbides was significantly larger than at vanadium carbides, which confirms the results presented in this work.

\subsection{Permeation}

Permeation tests were performed to determine the diffusion coefficients of the two alloys. The calculated average diffusion coefficients were for the $\mathrm{Ti}$ - and $\mathrm{V}$-containing ferritic alloys, respectively, $4.44 \times 10^{-10}$ and $1.53 \times 10^{-10} \mathrm{~m}^{2} / \mathrm{s}$. The Ti-containing alloy exhibited a slightly higher diffusion coefficient than the V-containing alloy. It seems the diffusivity is mainly governed by the ferritic matrix. The difference in diffusivity is rather limited and can, therefore, be excluded as a very relevant factor for variations in hydrogen degradation behavior of the different materials.

\subsection{Thermal Desorption Spectroscopy}

In order to further characterize the trapping behavior of the materials, TDS measurements were carried out. As such, the trapping capacity of the precipitates could be analyzed. To clearly visualize the precipitate related peak, the spectra obtained at a heating rate of $1200^{\circ} \mathrm{C} / \mathrm{h}$ are shown (Fig. 7). Deconvolution of the obtained results revealed the presence of two peaks for both alloys. The first peak was correlated to hydrogen trapped at the grain boundaries, solid solution atoms, and dislocations, while the small 2nd peak could be correlated to the presence of Ti- and V-based coherent particles. Takahashi et al. [35] showed that trapping occurs at the interfaces of titanium-based precipitates, while trapping in V-based precipitates has been claimed to occur both at the interface between carbide and matrix and at the carbon vacancies in the $\mathrm{V}_{4} \mathrm{C}_{3}$ precipitate $[11,38,40]$. It is not possible to make a distinction between those two $\mathrm{V}_{4} \mathrm{C}_{3}$ related traps in the TDS spectrum.

The amount of hydrogen released during the TDS measurement (heating to $900{ }^{\circ} \mathrm{C}$ ) corresponded closely to the amount of hydrogen measured during hot extraction (heating to $300^{\circ} \mathrm{C}$ ). This hydrogen is hence rather weakly trapped and possibly results from traps such as atoms in solid solution, grain boundaries, dislocations, and coherent particles or the elastic strain fields surrounding them. The Fe-C-V alloy exhibits a larger fraction of (semi-)coherent particles than $\mathrm{Fe}-\mathrm{C}-\mathrm{Ti}$, where multiple large precipitates are present. Additionally, a greater amount of free carbon and vanadium could be present in these alloys, due to the more efficient dissolution of particles during the austenitization step. These two factors could be responsible for the higher amount of diffusible hydrogen in Fe-C-V compared to Fe-C-Ti.

Pérez Escobar et al. [36] performed TDS measurements on gaseous charged TiC containing ferritic alloys and found a high temperature peak $\left(\mathrm{T}_{\max } \approx 580^{\circ} \mathrm{C}\right.$ ), which they attributed to irreversible trapping by the TiC precipitates. This peak did not change when the material was additionally electrochemically charged. This corresponds to the current results, where no high temperature peak is observed after electrochemical charging. However, these results in combination with the melt extraction results indicate that a certain amount of hydrogen is trapped

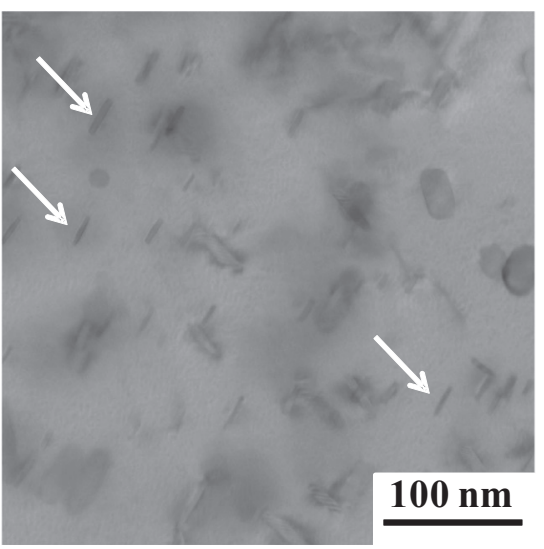

a)

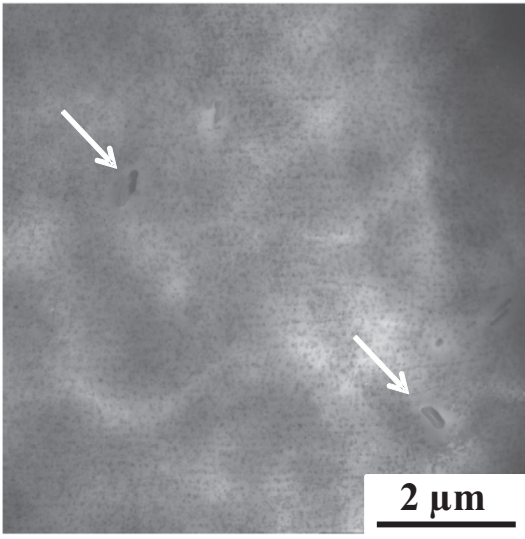

b)

Fig. 4. Bright field STEM images of a) small coherent $\mathrm{V}_{4} \mathrm{C}_{3}$, and b) larger incoherent $\mathrm{V}(\mathrm{C}, \mathrm{N})$ (indicated with arrows). 


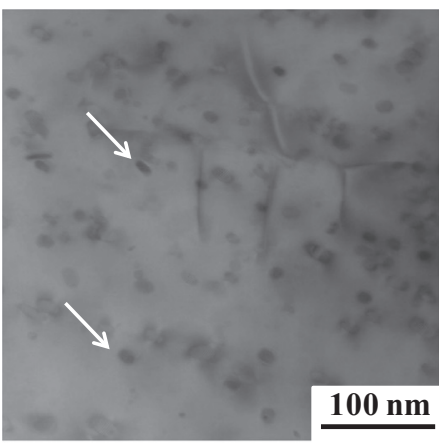

a)

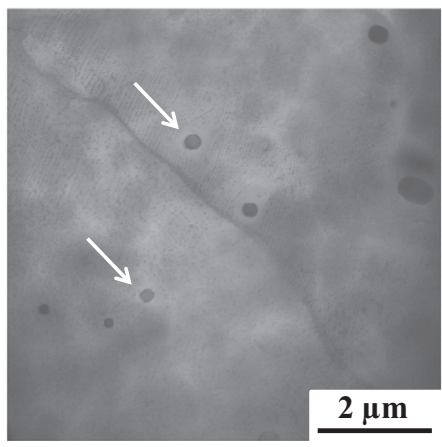

b)

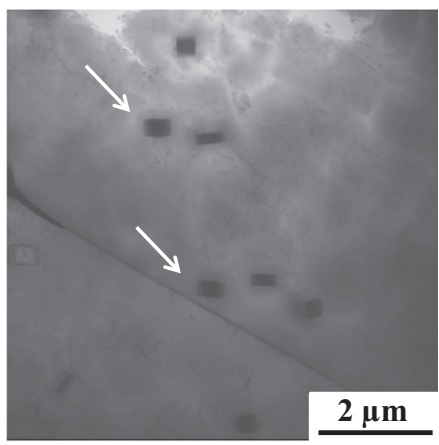

c)

Fig. 5. Bright field STEM images of a) small coherent TiC, b) larger spherical Ti(C,N), and c) square Ti(C,N) (indicated with arrows).

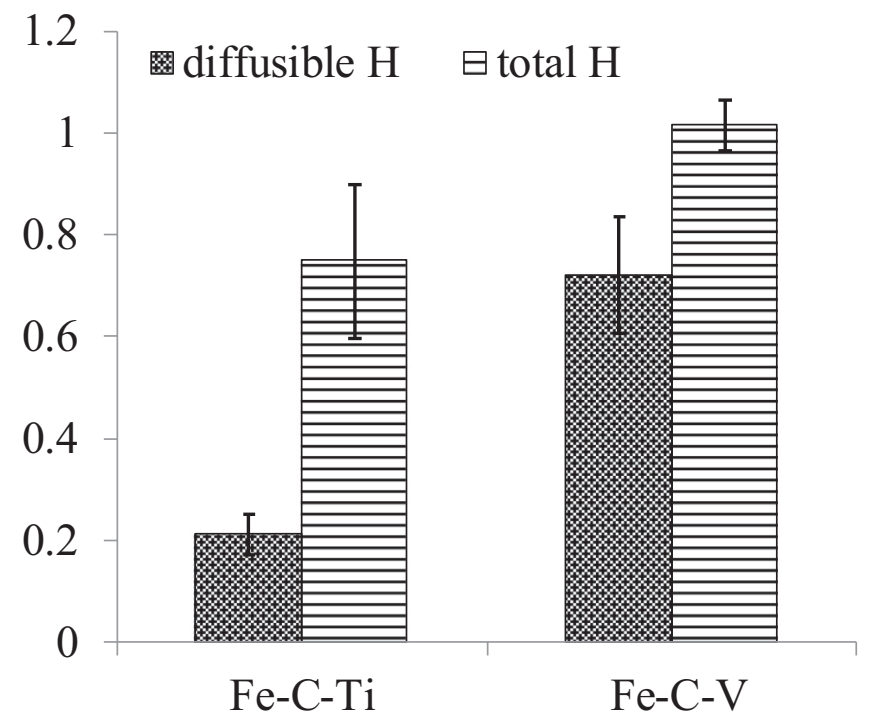

Fig. 6. Hot and melt extraction results of Fe-C-Ti and Fe-C-V in wppm.

within the material at very strong traps, which only release hydrogen at higher temperatures $\left(>900^{\circ} \mathrm{C}\right)$ or upon melting. Such traps could be related to hydrogen trapping inside the carbides/carbonitrides. Possibly the hydrogen is trapped at octahedral vacancies within the carbides/ carbonitrides, which trap hydrogen very strongly [18, 38]. If the formed carbonitrides are substoichiometric, they will exhibit more vacancies than the carbides [52] and trapping inside these precipitates

\section{Fe-C-Ti}

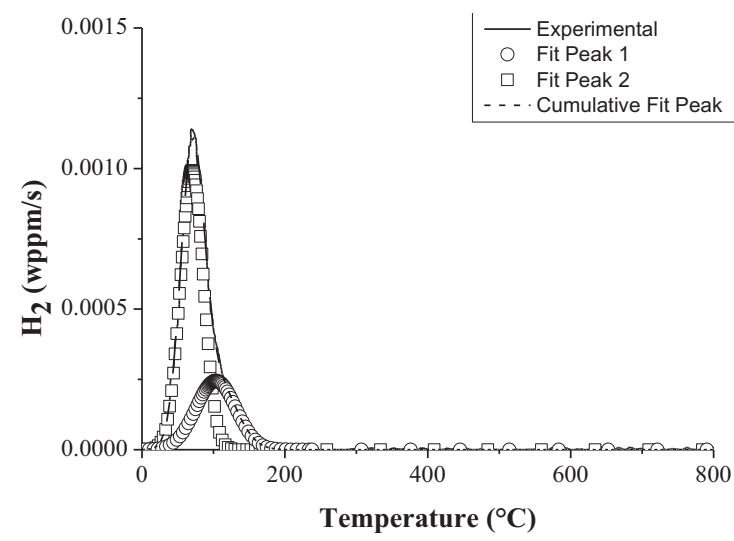

will be more likely [18]. Such type of irreversible hydrogen is present more prominently in Fe-C-Ti than in Fe-C-V. The results indicate that hydrogen was mostly trapped reversibly in $\mathrm{Fe}-\mathrm{C}-\mathrm{V}$, while irreversibly in Fe-C-Ti.

\subsection{Tensile Tests Combined With In-situ Electrochemical Charging}

Fig. 8 depicts the stress-strain curves of both materials tested in air and hydrogen saturated conditions. The Fe-C-V alloy is stronger and less ductile than the Fe-C-Ti alloy. The ductility loss of Fe-C-V is larger than the one of $\mathrm{Fe}-\mathrm{C}-\mathrm{Ti}$, i.e. $62 \%$ versus $53 \%$.

The two materials showed a difference in strength. The V-containing alloy exhibited a higher strength level, which can be related to the type of particles present in the alloy and the related strengthening mechanisms. Small coherent particles have a higher strengthening effect than large incoherent particles [53, 54]. Fe-C-Ti exhibited a larger amount of large carbides and carbonitrides than Fe-C-V. These particles only increase the strength level to a limited extent and reduce the amount of carbon and titanium able to form small particles.

The difference in the amount of diffusible hydrogen is relevant to explain the stronger sensitivity to hydrogen embrittlement of the Fe-C-V alloy as diffusible hydrogen plays a crucial role in the mechanical degradation [9]. Novak et al. [20] stated that fracture in hydrogencharged steel is not governed by the high-binding energy trap sites because these sites remain saturated with hydrogen, independent of loading and/or hydrogen exposure conditions; rather, it is dependent on the lattice sites and low-binding energy trap sites where the hydrogen concentration is function of time and loading. Hot extraction showed that a considerable fraction of hydrogen in $\mathrm{Fe}-\mathrm{C}-\mathrm{Ti}$ is trapped in

Fig. 7. TDS spectra of the Fe-C-Ti and Fe-C-V alloys (heating rate: $1200^{\circ} \mathrm{C} / \mathrm{h}$ ). 


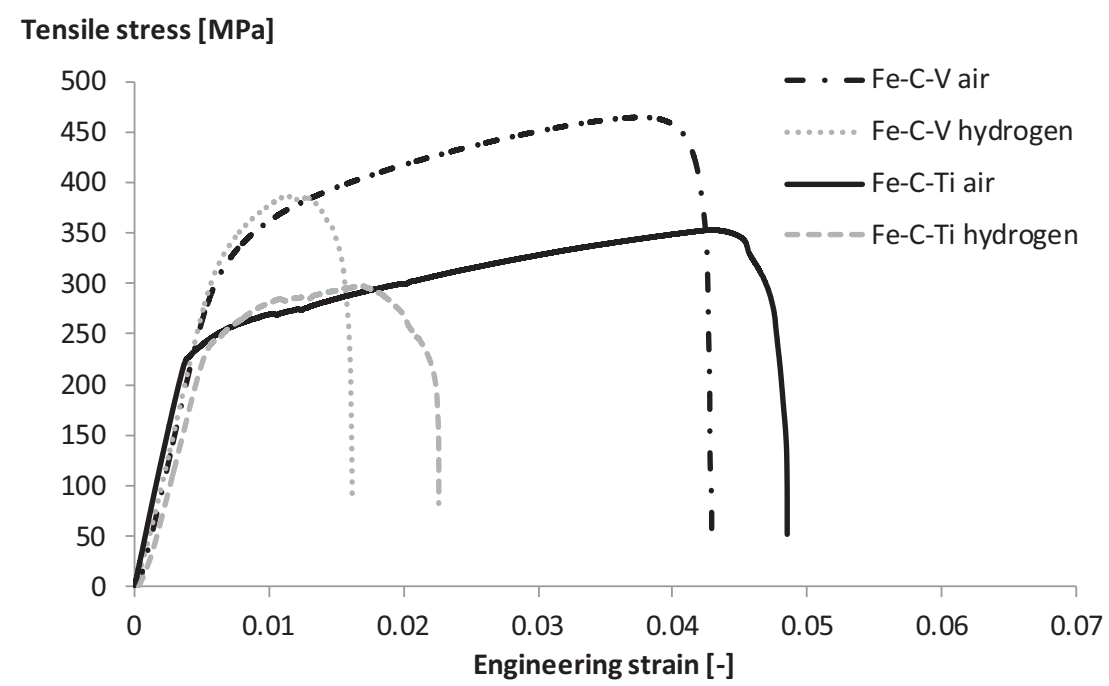

Fig. 8. Stress-strain curves (strain rate: $1.11 \times 10^{-5} \mathrm{~s}^{-1}$ ) of Fe-C-Ti and Fe-C-V tested until fracture in air and hydrogen charged conditions.

strong traps. Such traps do not release hydrogen under an applied stress field. On the other hand, Fe-C-V exhibited a large fraction of diffusible hydrogen in reversible traps, which release hydrogen under application of an external load. Such hydrogen diffuses towards critical areas, such as the high stress region ahead of the crack tip, which results in a locally increased embrittlement.

Both alloys exhibited a ductile fracture behavior in air. Fracture surface analysis indeed showed that fracture occurred by ductile microvoid coalescence (Fig. 9) and a considerable amount of necking was observed before fracture. The dimples in the Fe-C-V alloy were more flattened and present in a smaller number than those in the Fe-C-Ti alloy, confirming the slightly more brittle behavior as observed on the stress-strain curves. In both materials, broken particles were found inside some dimples (Fig. 10a). This observation indicates that particles act as crack initiation sites. Such particles are stronger than the surrounding ferritic matrix, which leads to strain incompatibility at these particles. Particles are, therefore, subjected to elevated stresses when the material is put under load. Fracture of the particles was dominantly observed rather than interface decohesion. In the Fe-C-Ti alloys, cracked particles were also observed near the fracture surface on the sides of the tensile samples (Fig. 10b). Such particles were approximately $2 \mu \mathrm{m}$ large and were identified by EDX as carbonitrides. The observed secondary cracks along the fracture surface were confined to the precipitates and did not propagate further into the ferrite. Cox et al. [55] and Shabrov et al. [56] stated that the particle size is a dominant factor for void nucleation following the rule that the stress required to fragment precipitates decreases with increasing precipitate size, which explains why secondary cracks are found in large carbonitride particles.

When subjected to hydrogen, both alloys showed a considerable decrease in ductility (Fig. 8), which was also reflected in the fracture surfaces (as illustrated for Fe-C-Ti in Fig. 11). Less necking of the samples occurred and the fracture surface showed more brittle behavior. Fish eyes were present on the fracture surfaces (Fig. 11b), which is a typical hydrogen embrittlement phenomenon. At the center of such a fish eye an inclusion is present, further fracture occurs in a pattern radiating away from the pupil. The inclusions were identified as carbonitrides by EDX (Fig. 12). No differences were found on the fracture surfaces when comparing both materials.

The surfaces of samples tested until tensile strength (interrupted tensile tests) in hydrogen charged condition were analyzed by SEM (Fig. 13). Secondary cracks formed ahead of the main crack, which was situated at the notch. Such cracks had a typical S-shape and were in previous studies identified as hydrogen assisted cracks [48, 57, 58]. EBSD was used to investigate these small cracks in more detail (Fig. 14). Cracking occurred dominantly transgranularly. The interaction with precipitates was only visible for Fe-C-Ti samples, since precipitates were too small in Fe-C-V to distinguish with SEM. Crack initiation and propagation were often found to be related to the presence of precipitate clusters (Fig. 13b). Cracks initiated both along and in precipitates, both in air as hydrogen charged condition. Precipitates typically have a brittle character, which makes crack initiation more likely to happen there than in the ductile matrix. The brittleness of the precipitates would play a greater role in Ti-based alloy, since the incoherent titanium precipitates are larger in size than any V-based

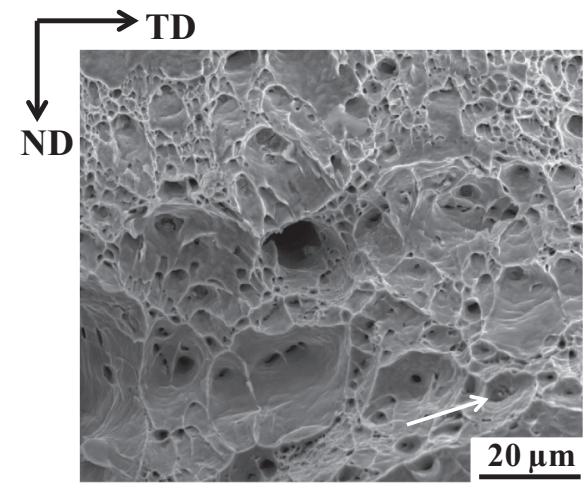

a)

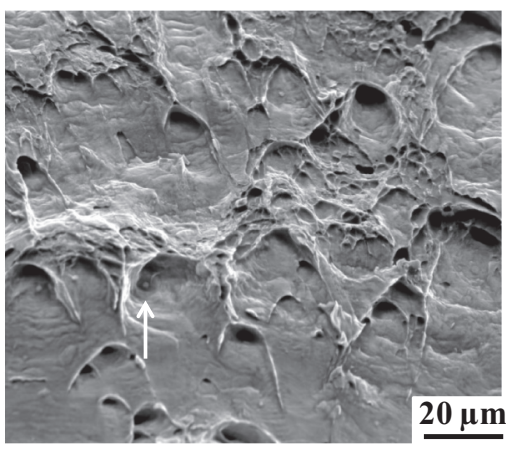

b)

Fig. 9. Fracture surface of a) Fe-C-Ti and b) Fe-C-V tensile tested in air. 


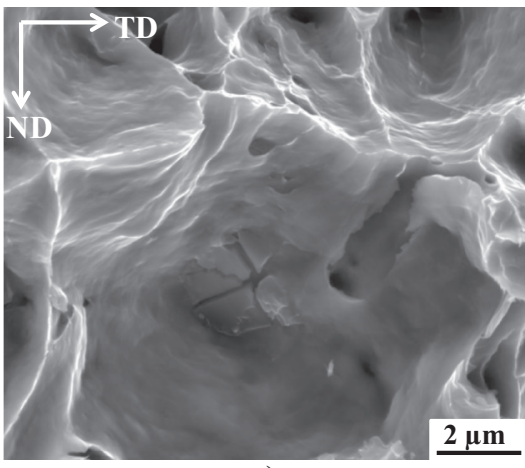

a)

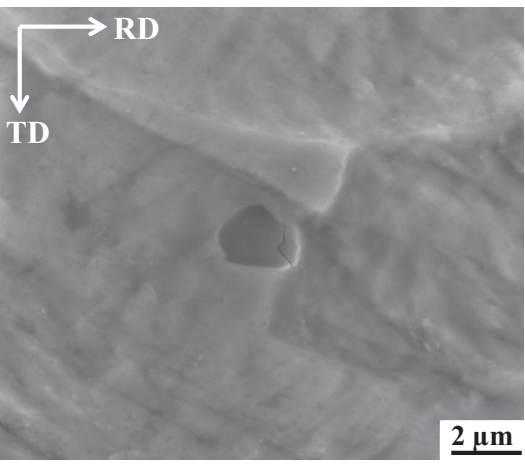

b)

Fig. 10. a) Fractured precipitate in dimple and b) Fractured carbonitride found near the fracture surface in Fe-C-Ti.

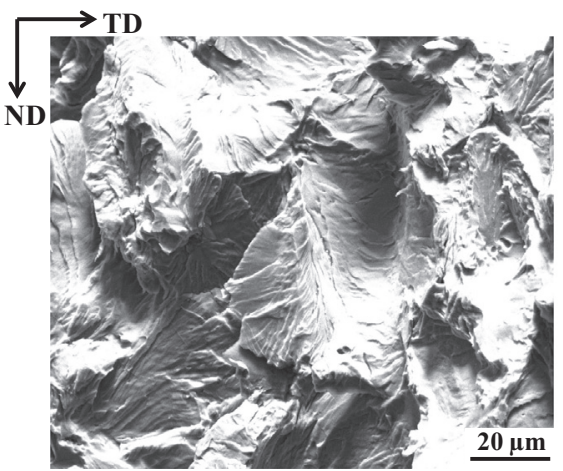

a)

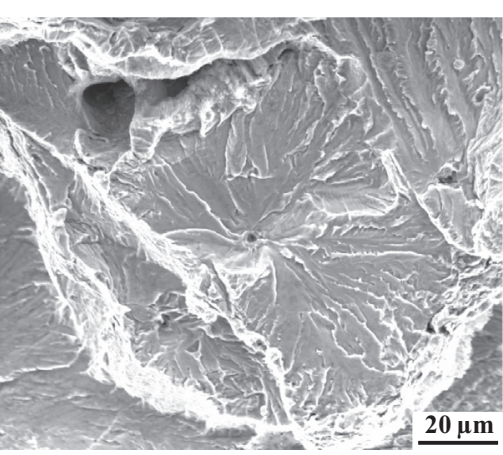

b)

Fig. 11. a) Fracture surface of the Fe-C-Ti alloy charged with hydrogen. b) Fisheye on the fracture surface of a hydrogen charged Fe-C-Ti sample.

precipitate and Shabrov et al. [56] stated that the stress required to fragment precipitates decreases with increasing precipitate size. Crack initiation kinetics are most likely enhanced in hydrogen charged condition, since hydrogen is expected to accumulate in and around the precipitates. Hydrogen present in precipitates will embrittle them by the HEDE mechanism [59]. While the presence of hydrogen during loading can have three possible effects enhancing precipitate interface crack initiation [20]: (i) hydrogen reduces the stress that impedes dislocation motion (HELP mechanism [60]), (ii) hydrogen trapped at dislocations [22, 61] reduces their repulsive interactions [62, 63],

\section{Carbon}

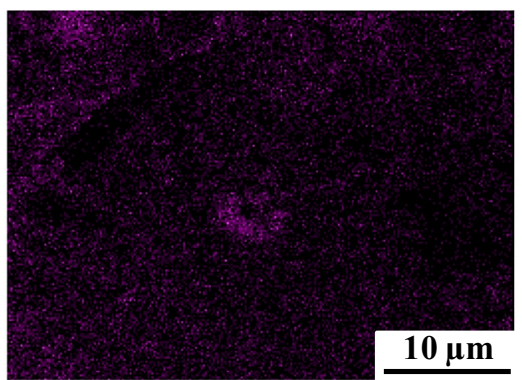

Titanium
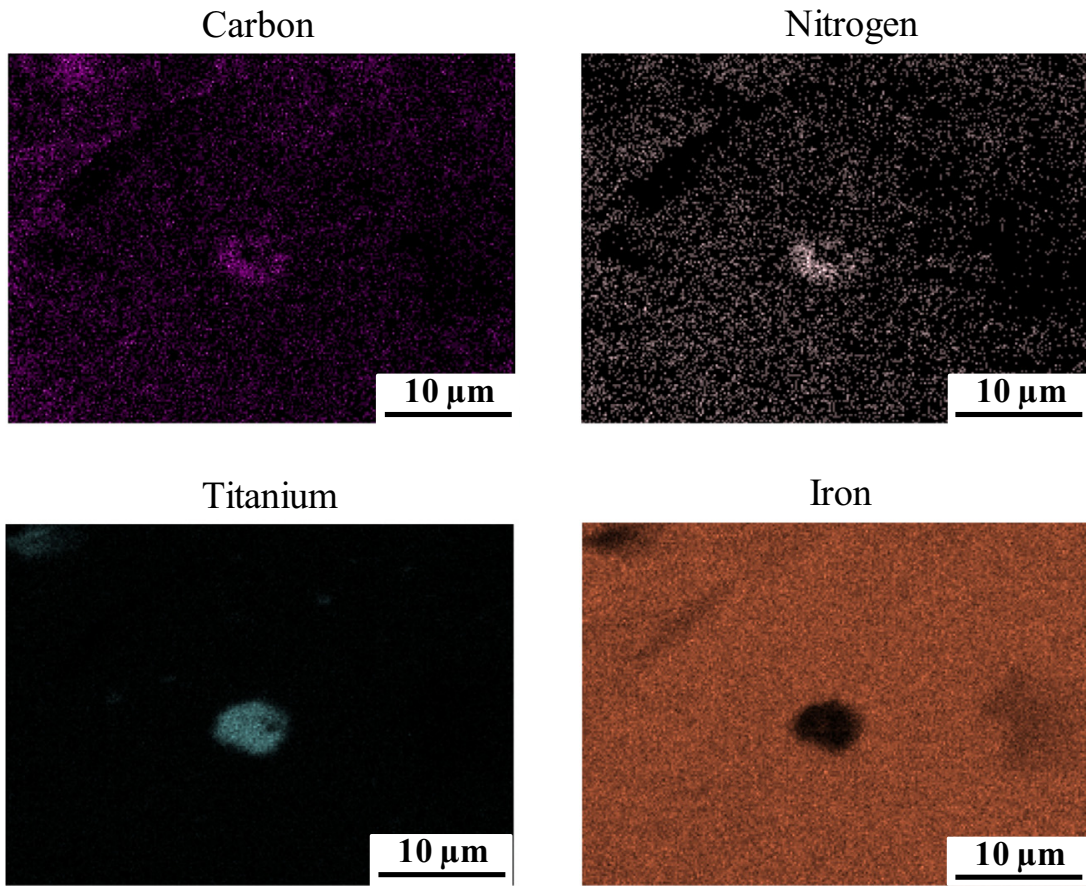

Iron

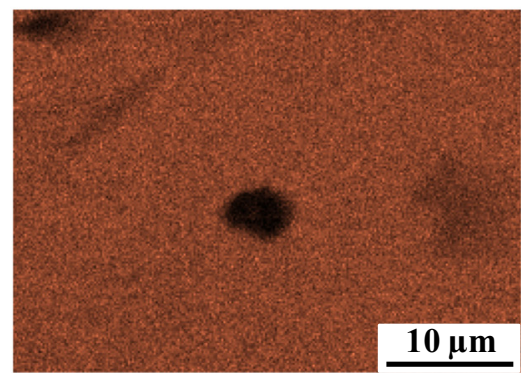

Fig. 12. Elemental mapping by EDX of center of a fisheye on the fracture surface of hydrogen charged Fe-C-Ti. 


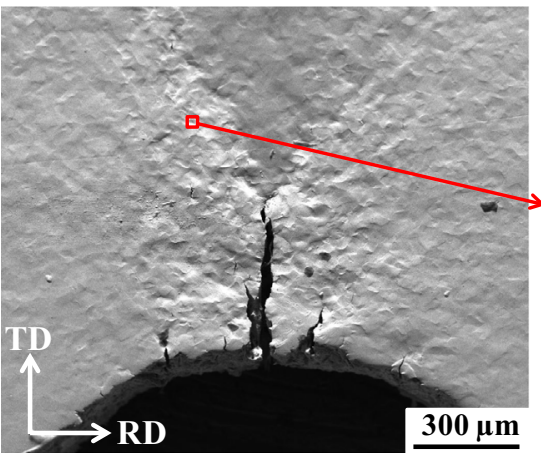

a)

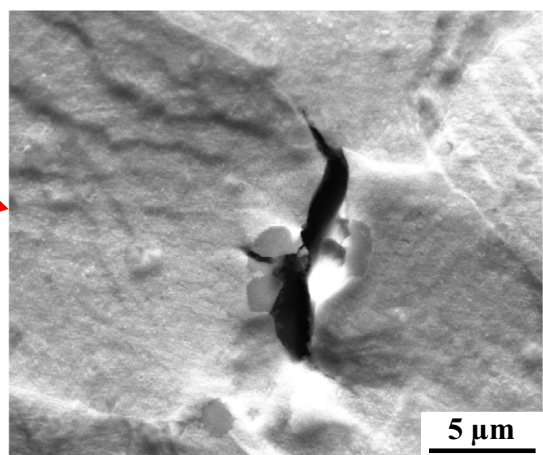

b)

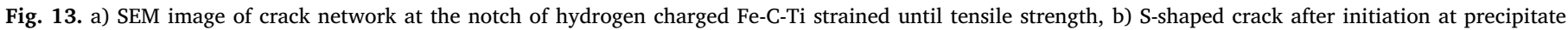
cluster.

which increases the number of dislocations in the pile-up. As such, the stress generated through impingement at the carbide/matrix interface is intensified, (iii) hydrogen lowers the reversible work of decohesion at carbide/matrix interface (HEDE [59] or hydrogen enhanced interface decohesion (HEIDE) [57] mechanism). These combined effects promote fracture along precipitate interfaces through a HELP-enhanced HEDE of interfaces.

Further propagation of the cracks is enhanced in the presence of hydrogen, since only initiated secondary cracks without further propagation were observed after tensile testing until tensile strength in air. The normally ductile ferrite matrix is embrittled due to hydrogen charging, which facilitates the propagation of initiated cracks. Further propagation of the cracks was even not controlled by microstructure or crystallography, but rather stress-controlled as is clear from the typical S-shape [48].

\subsection{Electrochemical Charging Tests Without External Load}

Samples were hydrogen charged without the application of an external load with varying charging conditions to assess the blister formation. Based on optical images the number of blisters was determined for the different charging conditions and the results are illustrated in Fig. 15. Blisters smaller than $100 \mu \mathrm{m}$ were not always counted, due to the limited resolution of optical images. The number of blisters increased for longer charging times and higher current densities as more hydrogen had entered the material in these cases. A higher amount of hydrogen introduces more damage as the critical amount of hydrogen required for initiation of damage is achieved at more places. The Fe-C-Ti alloy exhibited a large number of blisters homogeneously distributed over the sample surface. A large amount of small blisters was observed for this material in comparison to a simple ferritic matrix without precipitates [22] (Fig. 16). This implies that the Ti-based precipitates act as initiation sites for hydrogen induced cracks.

The Fe-C-V alloy exhibited a completely different blistering behavior than $\mathrm{Fe}-\mathrm{C}-\mathrm{Ti}$. The vanadium-based alloy exhibited a very limited amount of small blisters (Fig. 15b) for all charging conditions. However, for the Fe-C-V alloy another phenomenon occurred which competes with blistering. At high current densities during long charging times the outer surface turned black and at a certain point the surface even corroded away, leading to a reduction of sample thickness. No

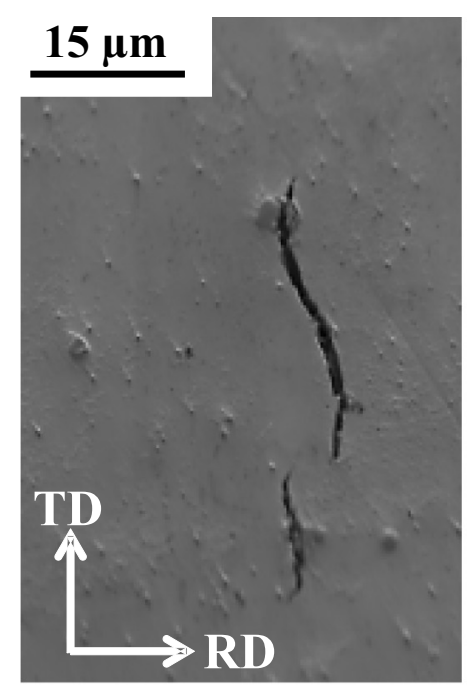

a)

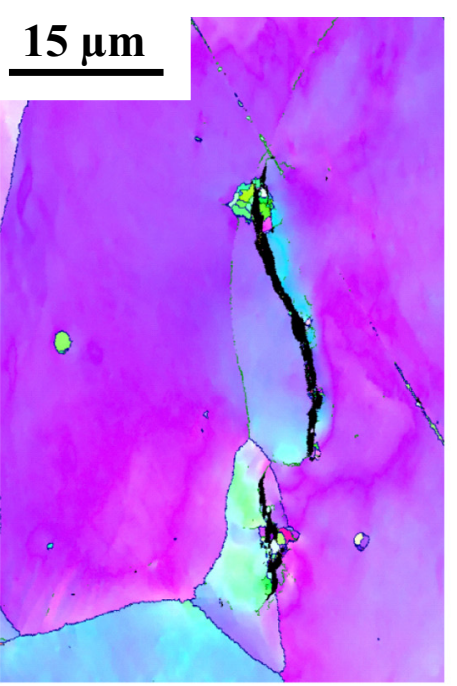

b)

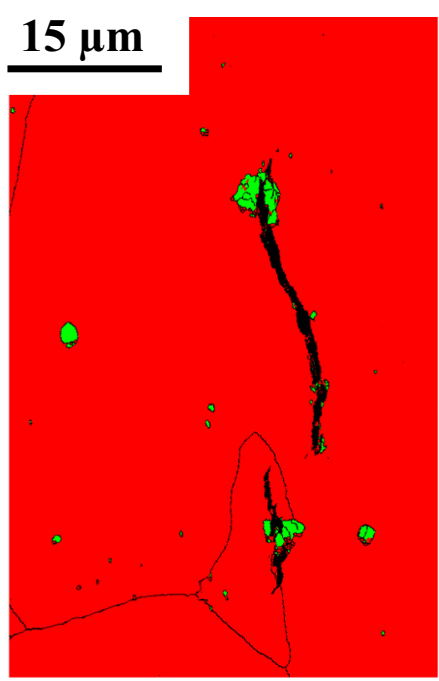

c)

Phase

Iron - Alpha

Titanium Carbide

Fig. 14. Hydrogen assisted cracks in Fe-C-Ti. a) SEM image, b) [001] // ND inverse pole figure map, and c) phase map. High angle grain boundaries ( $\geq 15^{\circ}$ ) are delineated in black. 


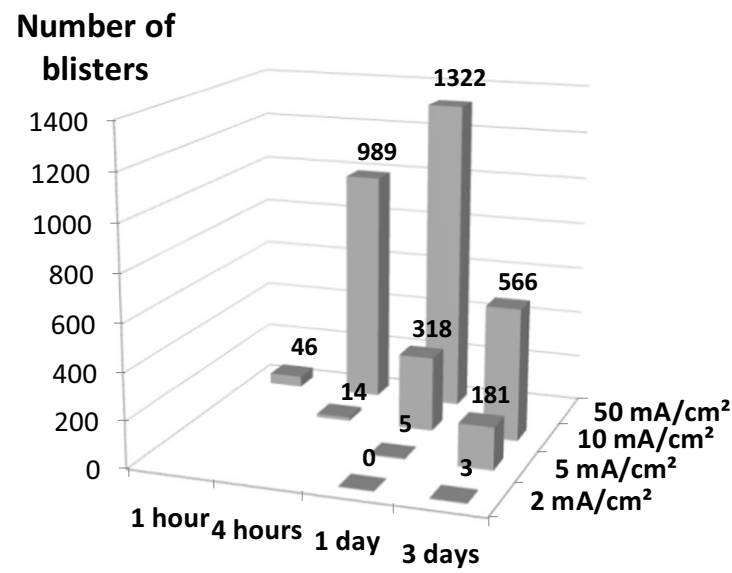

a)

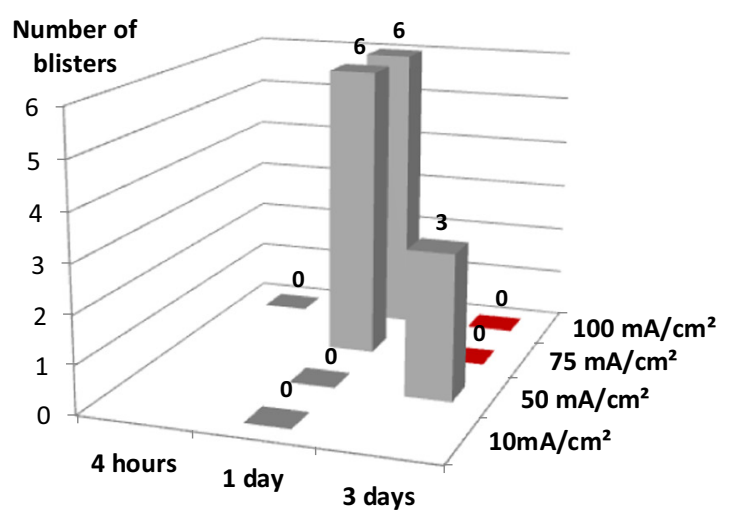

b)

Fig. 15. Number of blisters on a) Fe-C-Ti and b) Fe-C-V as a function of charging conditions.

blisters formed at such conditions. Magnetite is a corrosion product of iron that can be formed in acid environment and is characterized by a black appearance [64]. The hydrogen diffusivity through this thin oxide film is up to twelve orders of magnitude slower than in pure annealed iron [64]. The reaction possibly only plays a major role at high current densities when a lot of $\mathrm{H}^{+}$is being formed at the sample surface. Therefore, it is not straightforward to evaluate the actual blistering behavior of these alloys under these charging conditions. Nevertheless, the small number of blisters formed at low current densities in comparison to the Ti-based alloy insinuate that a uniform distribution of reversible traps which allocate the hydrogen innocuously will reduce the extent of hydrogen induced cracking. The precipitates in Fe-C-V are, therefore, most probably more resistant to blister initiation than Tibased precipitates. Hot and melt extraction results indicated that Tibased precipitates trap better than V-based precipitates. Ti-based precipitates trap hydrogen deeply and hydrogen will accumulate there until the critical hydrogen concentration is reached for crack initiation. The large amount of diffusible hydrogen in Fe-C-V is in this particular situation not harmful, contrary to what the performed tensile tests implied when studying hydrogen assisted cracking. These observations imply that the role of diffusible hydrogen in the responsible mechanisms of both phenomena is completely different. When assessing hydrogen assisted cracking in samples under load a larger presence of diffusible hydrogen increases the hydrogen embrittlement susceptibility, while this does not seem to disadvantage the hydrogen induced cracking and blistering behavior of a material significantly. On the other hand, efficient hydrogen trapping decreases the hydrogen embrittlement susceptibility, but does seem to enhance blister formation. However, some additional parameters need to be taken into account. Fe-C-V exhibited a higher strength than Fe-C-Ti, which makes blister formation for this alloy more difficult, since a higher pressure is necessary to reach the yield/fracture stress. Therefore, a higher hydrogen pressure build-up is required to cause blistering.

In order to further characterize the role of precipitates on blister formation, cross sections were studied by SEM and EBSD. No interaction between cracks and V-based precipitates could be established by SEM or EBSD, since the resolution did not allow visualization of these small carbonitrides and carbides. Cross section investigation in Fe-C-Ti showed that initiation was related to the intermediate and large titanium precipitates, i.e. TiC and Ti(C,N) (Fig. 17). The lack of such large precipitates in $\mathrm{Fe}-\mathrm{C}-\mathrm{V}$ could explain its higher resistivity to hydrogen induced blistering. Ren et al. [65] stated that Ti containing inclusions can act as nucleation sites for blisters. Initiation of new blisters was preferred over growth of already existing blisters in the present material, since only small blisters were observed in large number on the sample surface. Initiation of new blisters happened continuously throughout the charging procedure. The precipitates act as hydrogen traps, which implies that at these locations an increased amount of

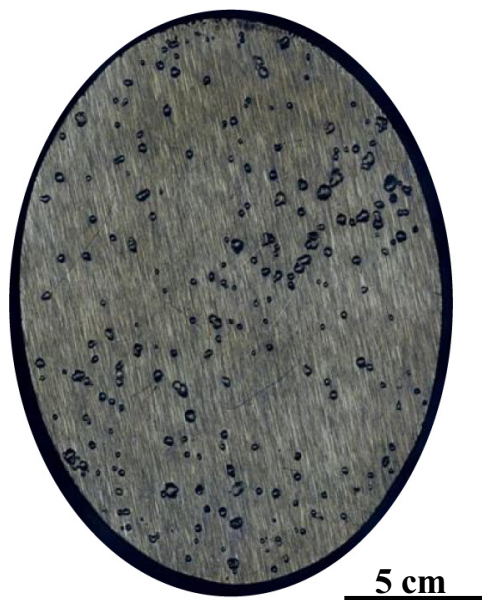

a)

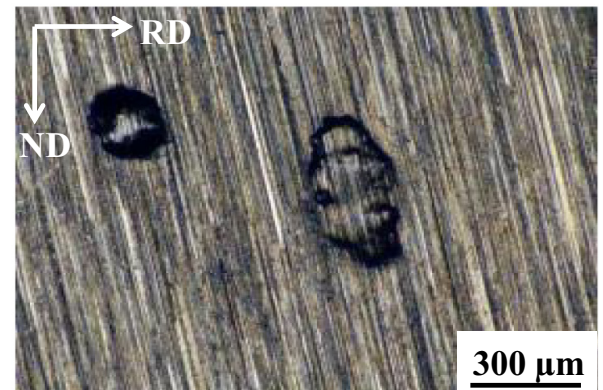

b)

Fig. 16. a) Overall optical microscopy image of Fe-C-Ti charged at $10 \mathrm{~mA} / \mathrm{cm}^{2}$ for 1 day. b) Magnification of blister. 


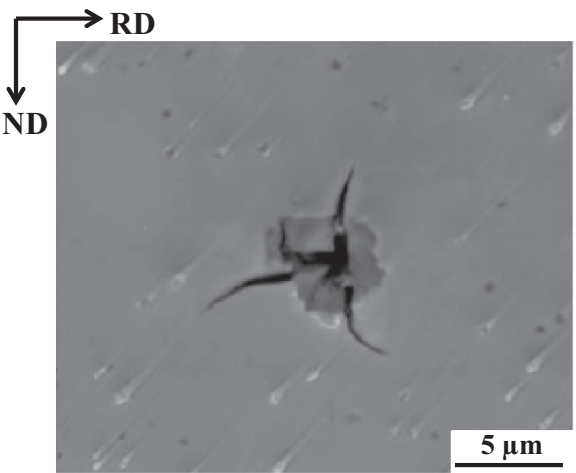

a)

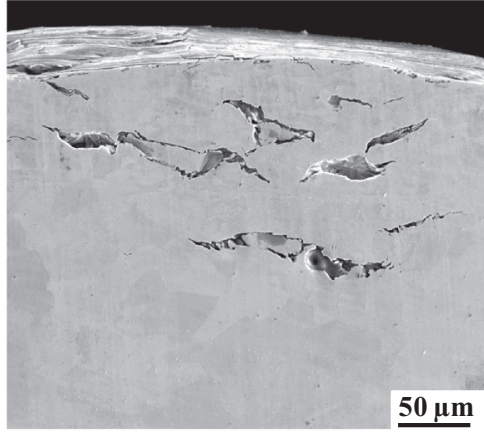

b)

Fig. 17. a) Blister initiation at large precipitates. b) cross section of blister clusters/blisters on blisters.

hydrogen is present and during continuous hydrogen charging under severe conditions, recombination of hydrogen atoms will occur. Blister clusters and blisters on blisters [22] were observed on the sample surface (Fig. 17b). These phenomena indicate that blister initiation near existing blisters is more advantageous than randomly in the matrix. Increased stress regions surround such earlier formed blisters, as such more hydrogen is attracted to the blister, making initiation locally more favorable [66].

Internal cracks often exhibited a branched morphology. Blisters propagated dominantly transgranular as visualized in the [001] // ND inverse pole figure map in Fig. 18. EBSD analysis of cracks allowed to visualize elevated orientation gradients surrounding blisters and in between branches, which validate the internal pressure theory [22, 24, 25] for blister formation and propagation (Fig. 18b). Crack interaction is clearly revealed by the high strain/stress regions in between two cracks, which was assessed by a KAM map in EBSD (Fig. 18c).

A clear interaction of cracks with large Ti-based precipitates was demonstrated as well with EBSD (Fig. 19). Most likely the hydrogen induced cracking initiated at the large carbides/carbonitrides, due to hydrogen build-up at the interface or in the precipitates. Precipitates

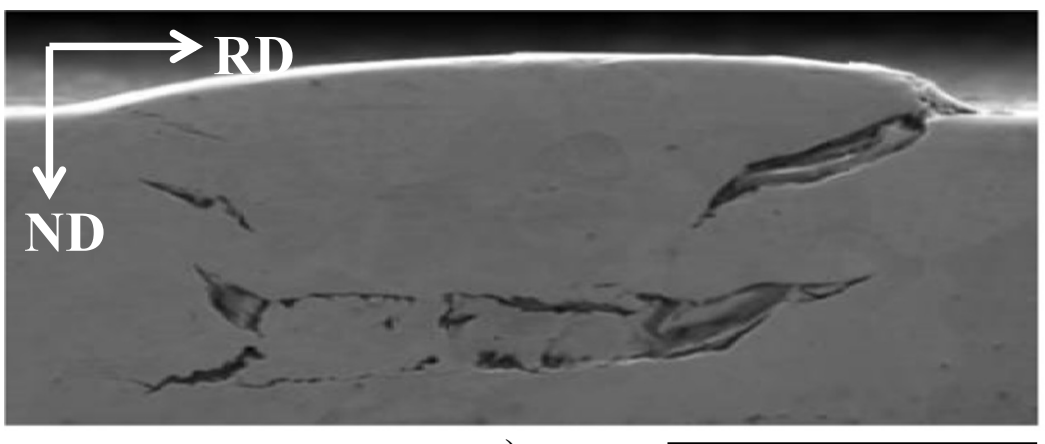

a)

$80 \mu \mathrm{m}$
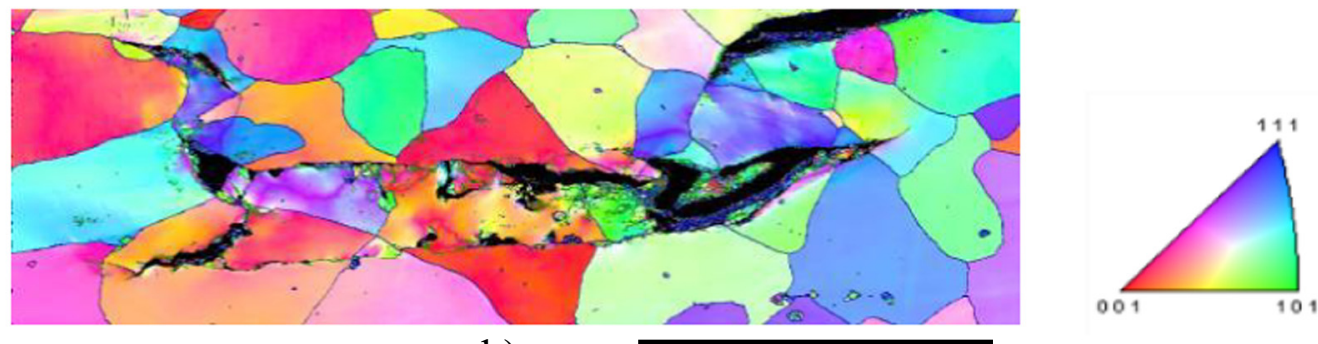

b)

$80 \mu \mathrm{m}$

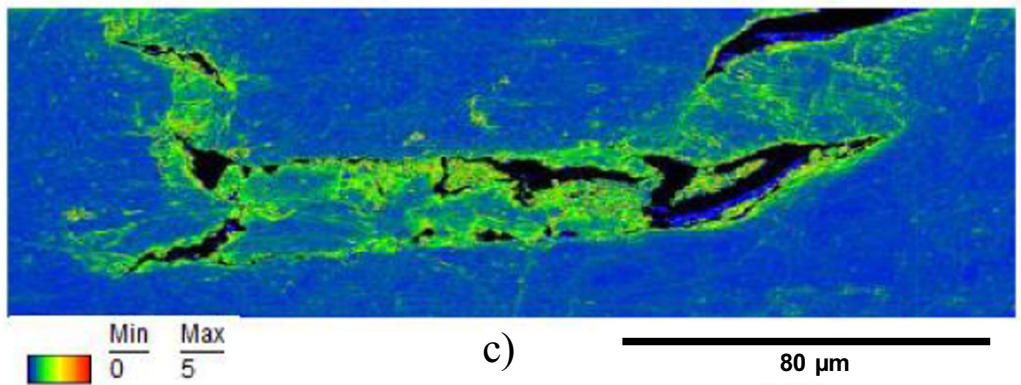

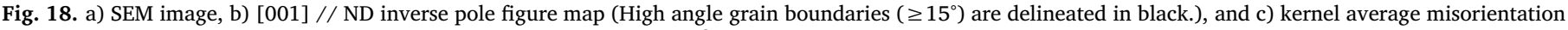
map of blister cross section in Fe-C-Ti charged for one day at $10 \mathrm{~mA} / \mathrm{cm}^{2}$. 


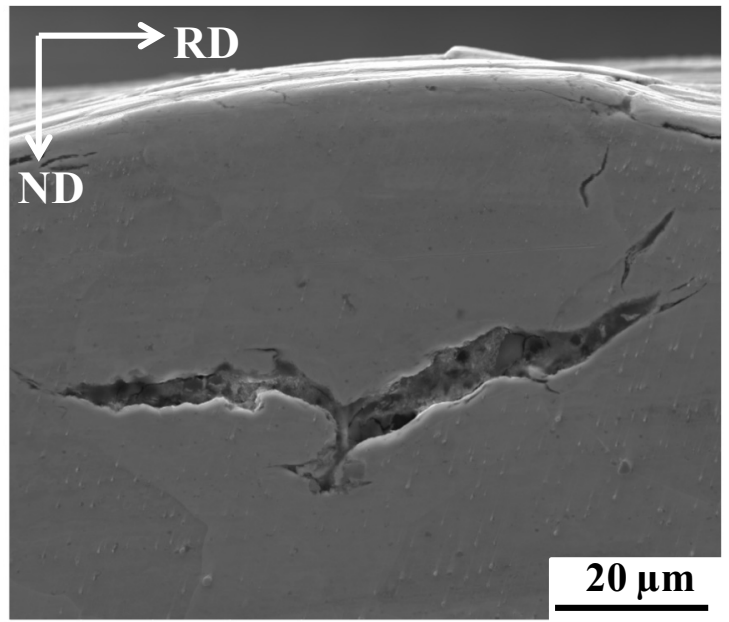

a)

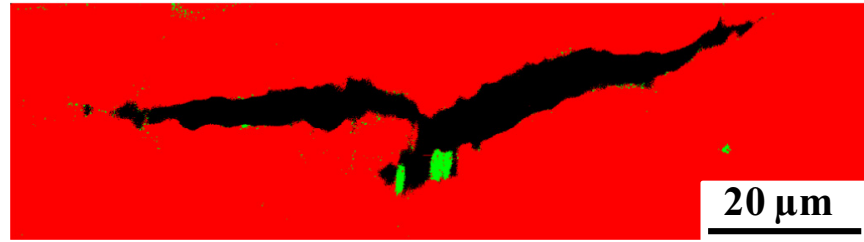

b)

Fig. 19. Crack interaction with Ti-based precipitates in Fe-C-Ti charged for one day at $10 \mathrm{~mA} / \mathrm{cm}^{2}$.

did not seem to have a significant influence on further crack propagation. Several precipitates were observed close to cracks, but the cracks did not deviate towards the precipitates. Propagation is rather controlled by the drive for internal pressure release at the surface or interaction with other cavities.

\section{Conclusions}

The effect of Ti- and V-based precipitates on two types of hydrogen induced damage were investigated in ferritic Fe-C-X (with $\mathrm{X}$ being $\mathrm{V}$ or Ti) alloys. Both alloys contained carbides and carbonitrides. The Tibased precipitate size distribution differed from the V-based precipitates; larger precipitates were present in Fe-C-Ti.

Fe-C-Ti trapped absorbed hydrogen strongly, while a large amount of diffusible hydrogen was found in Fe-C-V. The diffusion coefficients did not differ significantly. TDS results indicated that a certain amount of hydrogen was trapped reversibly at grain boundaries, solid solution atoms, dislocations and coherent precipitates. The remaining hydrogen was trapped very strongly, in traps which release hydrogen only upon heating above $900{ }^{\circ} \mathrm{C}$ or melting of the sample.

Tensile tests with in-situ electrochemical charging on saturated samples showed that large precipitates, which most probably act as strong hydrogen traps, have a dominant role in crack initiation, this is however also the case when tested in air. Crack initiation kinetics are most probably enhanced when hydrogen is present in and around these precipitates. Reversible traps and the resulting presence of diffusible hydrogen facilitate the crack propagation by providing hydrogen to the crack tip surroundings. Blister studies demonstrated that irreversible traps have a dominant role in crack initiation while reversible traps delay crack initiation and propagation. Crack propagation is governed by the internal pressure, rather than by the microstructure. Diffusible hydrogen clearly plays a different role in both mechanisms, and therefore, choosing certain types of precipitates to improve the hydrogen induced degradation resistance should be application dependent. Hydrogen induced cracking and blistering is unlikely to occur at low hydrogen charging conditions, where the driving force is insufficient to cause hydrogen gas precipitation in the material, but where there is sufficient hydrogen to cause embrittlement.

\section{Acknowledgements}

The authors wish to thank the Agency for Innovation by Science and Technology in Flanders (IWT) for support (Project no. SB141399), the UGent postdoctoral fellowship via grant nr BOF01P03516, the Special Research Fund (BOF), UGent (BOF15/BAS/06) and the MaDuRosprogram (SIM), part of the DeMoPreCI-MDT project.

\section{Data availability}

The raw/processed data required to reproduce these findings cannot be shared at this time as the data also forms part of an ongoing study.

\section{References}

[1] J.P. Hirth, The role of hydrogen in enhancing plastic instability and degrading fracture toughness in steels, in: A.W. Thompson, N.R. Moody (Eds.), Hydrogen Effects in Materials, TMS, Warrendale, 1996, pp. 507-522.

[2] T.J. Carter, L.A. Cornish, Hydrogen in metals, Eng. Fail. Anal. 8 (2001) 113-121.

[3] Mechanism of corrosion fatigue, ASM Handbook, Volume 19: Fatigue and Fracture, ASM International, 1996, pp. 185-192.

[4] G.M. Pressouyre, I.M. Bernstein, An example of the effect of hydrogen trapping on hydrogen embrittlement, Metall. Trans. A. 12 (1981) 835-844.

[5] H. Asahi, D. Hirakami, S. Yamasaki, Hydrogen trapping behavior in vanadiumadded steel, ISIJ Int. 43 (2003) 527-533.

[6] G.M. Pressouyre, I.M. Bernstein, A quantitative analysis of hydrogen trapping, Metall. Trans. A. 9 (1978) 1571-1580.

[7] M.I. Luppo, J. Ovejero-Garcia, Application of the hydrogen-permeation method to the study of carbide precipitation kinetics in a low-carbon martensite, Mater. Charact. 40 (1998) 189-196.

[8] T. Depover, O. Monbaliu, E. Wallaert, K. Verbeken, Effect of Ti, Mo and Cr based precipitates on the hydrogen trapping and embrittlement of Fe-C-X Q\&T alloys, Int. J. Hydrog. Energy 40 (2015) 16977-16984.

[9] G.M. Pressouyre, Trap theory of hydrogen embrittlement, Acta Metall. 28 (1980) 895-911.

[10] T. Depover, K. Verbeken, The detrimental effect of hydrogen at dislocations on the hydrogen embrittlement susceptibility of Fe-C-X alloys: an experimental proof of the HELP mechanism, Int. J. Hydrog. Energy 43 (2018) 3050-3061.

[11] T. Depover, K. Verbeken, Evaluation of the effect of V4C3 precipitates on the hydrogen induced mechanical degradation of Fe-C-V alloys, Mater. Sci. Eng. 675 (2016) 299-313.

[12] G.L. Spencer, D.J. Duquette, The role of vanadium carbide traps in reducing the hydrogen embrittlement susceptibility of high strength alloy steels, Technical Report, US Army Armament Research, 1998.

[13] A. Nagao, M.L. Martin, M. Dadfarnia, P. Sofronis, I.M. Robertson, The effect of nanosized (Ti,Mo)C precipitates on hydrogen embrittlement of tempered lath martensitic steel, Acta Mater. 74 (2014) 244-254.

[14] T. Depover, K. Verbeken, The effect of TiC on the hydrogen induced ductility loss and trapping behavior of Fe-C-Ti alloys, Corros. Sci. 112 (2016) 308-326.

[15] F.G. Wei, K. Tsuzaki, Quantitative analysis on hydrogen trapping of TiC particles in steel, Metall. Mater. Trans. A 37 (2006) 331-353.

[16] T. Depover, K. Verbeken, Thermal desorption spectroscopy study of the hydrogen trapping ability of W based precipitates in a Q\&T matrix, Int. J. Hydrog. Energy 43 (2018) 5760-5769.

[17] T. Depover, D. Pérez Escobar, E. Wallaert, Z. Zermout, K. Verbeken, Effect of in-situ hydrogen charging on the mechanical properties of advanced high strength steels, Int. J. Hydrog. Energy 39 (2014) 4647-4656.

[18] D. Di Stefano, R. Nazarov, T. Hickel, J. Neugebauer, M. Mrovec, C. Elsässer, Firstprinciples investigation of hydrogen interaction with TiC precipitates in alpha-Fe, Phys. Rev. B 93 (2016) 184108.

[19] X.C. Ren, Q.J. Zhou, G.B. Shan, W.Y. Chu, J.X. Li, Y.J. Su, L.J. Qiao, A nucleation mechanism of hydrogen blister in metals, Metall. Mater. Trans. 39A (2008) 87-97.

[20] P. Novak, R. Yuan, B. Somerday, P. Sofronis, R. Ritchie, A statistical, physicalbased, micro-mechanical model of hydrogen-induced intergranular fracture in steel, J. Mech. Phys. Solids 58 (2010) 206-226.

[21] D. Pérez Escobar, C. Miñambres, L. Duprez, K. Verbeken, M. Verhaege, Internal and surface damage of multiphase steels and pure iron after electrochemical hydrogen charging, Corros. Sci. 53 (2011) 3166-3176.

[22] A. Laureys, E. Van den Eeckhout, R. Petrov, K. Verbeken, Effect of deformation and charging conditions on crack and blister formation during electrochemical hydrogen charging, Acta Mater. 127 (2017) 192-202.

[23] E. De Bruycker, S. De Vroey, S. Huysmans, J. Stubbe, Phenomenology of hydrogen flaking in nuclear reactor pressure vessels, Materials Testing 56 (2014) 439-444.

[24] C. Zapffe, C. Sims, Hydrogen embrittlement, internal stress and defects in steel, TMS-AIME 145 (1941) 225-232.

[25] A.S. Tetelman, W.D. Robertson, Direct observation and analysis of crack 
propagation in iron-3\% silicon single crystals, Acta Metall. 11 (1963) 415-426.

[26] M. Elboujdaini, Hydrogen-induced cracking and sulfide stress cracking, in: R. Winston Revie (Ed.), Uhlig's Corrosion Handbook, John Wiley \& Sons, Inc., Hoboken, NJ, 2011, pp. 183-194.

[27] R. Gibala, A.J. Kumnick, R. Gibala, R.F. Hehemann (Eds.), Hydrogen Embrittlement and Stress Corrosion Cracking, ASM, Metals Park, OH, 1985, p. 62.

[28] M. Tanimura, Y. Ishizawa, T. Shimada, Nippon Kokan Tech. Rep., Overseas 38 (1983) 42.

[29] M. Nagumo, M. Nakamura, K. Takai, Hydrogen thermal desorption relevant to delayed-fracture susceptibility of high-strength steels, Metall. Mater. Trans. A 32 (2001) 339-347.

[30] M.C. Tiegel, M.L. Martin, A.K. Lehmberg, M. Deutges, C. Borchers, R. Kirchheim, Crack and blister initiation and growth in purified iron due to hydrogen loading, Acta Mater. 115 (2016) 24-34.

[31] M. Iino, The extension of hydrogen blister-crack array in linepipe steels, Metall. Trans. A. 9 (1978) 1581-1590.

[32] F. Wei, T. Hara, K. Tsuzaki, Precise determination of the activation energy for desorption of hydrogen in two Ti-added steels by a single thermal-desorption spectrum, Metall. Mater. Trans. B Process Metall. Mater. Process. Sci. 35B (2004) 587-597.

[33] G.M. Pressouyre, I.M. Bernstein, A kinetic trapping model for hydrogen-induced cracking, Acta Metall. 27 (1979) 89-100.

[34] P. Dey, R. Nazarov, T. Hickel, J. Neugebauer, D. Haley, P.-P. Choi, T. Evertz, Z. Georgeou, D. Mirkovic, F. Klose, Hydrogen-carbide interactions in steels: ab-initio calculations combined with experiment, Steely Hydrogen Conference Proceedings, 2014, pp. 226-238.

[35] J. Takahashi, K. Kawakami, Y. Kobayashi, T. Tarui, The first direct observation of hydrogen trapping sites in TiC precipitation-hardening steel through atom probe tomography, Scr. Mater. 63 (2010) 261-264.

[36] D. Pérez Escobar, E. Wallaert, L. Duprez, A. Atrens, K. Verbeken, Thermal desorption spectroscopy study of the interactio of hydrogen with TiC precipitates, Met. Mater. Int. 19 (2013) 741-748.

[37] T. Hickel, R. Nazarov, E.J. McEniry, G. Leyson, B. Grabowski, J. Neugebauer, Ab initio based understanding of the segregation and diffusion mechanisms of hydrogen in steels, JOM 66 (2014) 1399-1405.

[38] J. Takahashi, K. Kawakami, T. Tarui, Direct observation of hydrogen-trapping sites in vanadium carbide precipitation steel by atom probe tomography, Scr. Mater. 67 (2012) 213-216.

[39] T. Yokota, T. Shiraga, Evaluation of hydrogen content trapped by vanadium precipitates in steel, ISIJ Int. 43 (2003) 534-538.

[40] G.M. Pressouyre, A classification of hydrogen traps in steel, Metall. Trans. A. 10 (1979) 1571-1573.

[41] B. Malard, B. Remy, C. Scott, A. Deschamps, J. Chêne, T. Dieudonné, T. Mathon, Hydrogen trapping by VC precipitates and structural defects in a high strength Fe-Mn-C steel studied by small-angle neutron scattering, Mater. Sci. Eng. A 536 (2012) 110-116.

[42] K. Kawakami, T. Matsumiya, Numerical analysis of hydrogen trap state by TiC and V4C3 in bcc-Fe, ISIJ Int. 52 (2012) 1693-1697.

[43] S. Yamasaki, Modelling Precipitation of Carbides in Martensitic Steels, Doctora thesis, p. Cambridge (2004).

[44] D. Hardie, Liu Su'e, The effect of stress concentration on hydrogen embrittlement of a low alloy steel, Corros. Sci. 38 (1996) 721-733.

[45] E. Akiyama, K. Matsukado, M. Wang, K. Tsuzaki, Evaluation of hydrogen entry into high strength steel under atmospheric corrosion, Corros. Sci. 52 (2010) 2758-2765.
[46] M.A.V. Devanathan, Z.O.J. Stachurski, The adsorption and diffusion of electrolytic hydrogen in palladium, Proc. R. Soc. Lond. A 270 (1962) 90-102.

[47] P. Doig, G.T. Jones, A model for the initiation of hydrogen embrittlement cracking at notches in gaseous hydrogen environments, Metall. Trans. A. 8A (1977) 1993-1998.

[48] A. Laureys, T. Depover, R. Petrov, K. Verbeken, Influence of sample geometry and microstructure on the hydrogen induced cracking characteristics under uniaxial load, Mater. Sci. Eng. A 690 (2017) 88-95.

[49] V. Randle, Electron backscatter diffraction: strategies for reliable data acquisition and processing, Mater. Charact. 60 (2009) 913-922.

[50] P.D. Dellist, The principles of STEM imaging, in: S. Pennycook, P. Nellist (Eds.), Scanning Transmission Electron Microscopy, Springer, New York, 2011, pp. 91-115.

[51] F.G. Wei, K. Tsuzaki, Hydrogen trapping phenomena in martensitic steels, in: R.P. Gangloff, B.P. Somerday (Eds.), Gaseaous Hydrogen Embrittlement of Materials in Energy Technologies, Woodhead, Cambridge, 2012, pp. 493-525.

[52] M. Guemmaz, G. Moraitis, A. Mosser, M.A. Khan, J.C. Parlebas, Band structure of substoichiometric titanium nitrides and carbonitrides: spectroscopical and theoretical investigations, J. Phys. Condens. Matter 9 (1997) 8453-8463.

[53] G. Gottstein, Physical Foundations of Materials Science, Springer Berlin Heidelberg, New York, 2004.

[54] S. Vervynckt, P. Thibaux, K. Verbeken, Effect of niobium on the microstructure and mechanical properties of hot rolled microalloyed steels after recrystallization-controlled rolling, Met. Mater. Int. 18 (2012) 37-46.

[55] T.B. Cox, J.R. Low, An investigation of the plastic fracture of AISI 4340 and 18 Nickel-200 grade maraging steels, Metall. Trans. 5 (1974) 1457-1470.

[56] M.N. Shabrov, C.L. Briant, A. Needleman, S. Kim, E. Sylven, D.H. Sherman, L. Chuzhoy, Void nucleation by inclusion cracking, Metall. Mater. Trans. A 35 (2004) 1745-1755.

[57] A. Laureys, T. Depover, R. Petrov, K. Verbeken, Microstructural characterization of hydrogen induced cracking in TRIP-assisted steel by EBSD, Mater. Charact. 112 (2016) 169-179.

[58] A. Laureys, T. Depover, R. Petrov, K. Verbeken, Characterization of hydrogen induced cracking in TRIP-assisted steels, Int. J. Hydrog. Energy 40 (2015) 16901-16912.

[59] A.R. Troiano, The role of hydrogen and other interstitials in the mechanical behaviour of metals, Trans. ASM 52 (1960) 54-80.

[60] C.D. Beachem, A new model for hydrogen-assisted cracking, Metall. Trans. 3 (1972) 437-451.

[61] E. Van den Eeckhout, A. Lauryes, Y. Van Ingelgem, K. Verbeken, Hydrogen permeation through deformed and heat-treated Armco pure iron, Mater. Sci. Technol. 33 (2017) 1515-1523.

[62] P. Sofronis, H.K. Birnbaum, Mechanics of the hydrogen/dislocation/impurity interactions-I. Increasing shear modulus, Mech. Phys. Solids 43 (1995) 49-90.

[63] I.M. Robertson, The effect of hydrogen on dislocation dynamics, Eng. Fract. Mech. 68 (2001) 671-692.

[64] H. Bhadeshia, Prevention of hydrogen embrittlement in steels, ISIJ Int. 56 (2016) 24-36.

[65] X. Ren, W. Chu, J. Li, Y. Su, L. Qiao, The effects of inclusions and second phase particles on hydrogen-induced blistering in iron, Mater. Chem. Phys. 107 (2008) 231-235.

[66] A. Griesche, E. Dabah, T. Kannengiesser, N. Kardjilov, A. Hilger, I. Manke, Threedimensional imaging of hydrogen blister in iron with neutron tomography, Acta Mater. 78 (2014) 14-22. 